\title{
Primeiros socorros na escola: conhecimento dos professores
}

\section{First aid at school: teacher knowledge}

\author{
${ }^{1}$ Elaine Viana Cabral elainevc@hotmail.com \\ ${ }^{2}$ Maria de Fátima Alves Oliveira
}

\section{RESUMO}

As crianças em idade escolar são vulneráveis aos acidentes e mudanças do ambiente domiciliar para o escolar podem interferir em seus padrões de resposta as situações de risco. Acidentes na infância são comuns podendo também ocorrer em ambiente escolar, o que justifica a necessidade de noções sobre primeiros socorros pelos professores ali presentes. O objetivo deste estudo foi investigar o conhecimento dos professores sobre primeiros socorros. Trata-se de um estudo de campo com abordagem quali-quantitativa, realizado após a aprovação do CoEPS da UNIFOA sob n ${ }^{3}$ 31469014.4.0000.5237. Participaram da pesquisa 31 docentes do ensino básico do município de Lorena, São Paulo. Para coleta de dados foi utilizado um instrumento contendo perguntas abertas e de múltipla escolha sobre primeiros socorros, elaborado pelas autoras. Dos 31 participantes da pesquisa, 22 afirmaram já ter vivenciado situações de acidentes na escola que exigissem conhecimentos sobre o assunto. Os agravos que geraram maior número de respostas incorretas foram sangramento nasal, quebraduras e engasgamento. Os achados evidenciaram a necessidade de uma capacitação destes professores a respeito do tema primeiros socorros.

Palavras-chave: Primeiros socorros. Enfermagem. Docentes.

\begin{abstract}
The school children are vulnerable to accidents and changes in the home environment to the school can influence their response patterns risk situations. Accidents in childhood are common and may also occur in the school environment, which justifies the need for notions of first aid by teachers in attendance. The aim of this study was to investigate the teachers' knowledge of first aid. It is a field study with qualitative and quantitative approach, performed after the approval of the CoEPS UNIFOA under no 31469014.4.0000.5237. The participants were 31 teachers of basic education in the city of Lorena, São Paulo. For data collection was used an instrument with open questions and multiple choice on first aid, developed by the authors. Of the 31 participants, 22 said they had experienced situations of accidents at school that required knowledge on the subject. The grievances that generated higher number of incorrect answers were nosebleeds, quebraduras and choking. The results show the need for training of these teachers about the first aid topic.
\end{abstract}

Keywords: First aid. Nursing. Teachers.

1 UniFOA

2 Fundação Oswaldo Cruz 


\section{INTRODUÇÃO}

Primeiros socorros consistem no atendimento imediato realizado pela população em geral ao indivíduo que se encontre doente ou ferido, tendo dois objetivos: ajudar a pessoa a se recuperar mais rápido ou manter a pessoa viva até a chegada do serviço médico pré hospitalar. É considerado um tema de grande relevância pelo fato que muitos agravos à saúde acontecem diariamente no trânsito, nos domicílios, no ambiente de trabalho, nas escolas e em diversos lugares (VERONESE et al., 2010; VARELLA; JARDIM, 2011).

Ao se deparar com uma situação de emergência a solidariedade é o sentimento que impulsiona grande parte da população a ajudar as vítimas, entretanto, muitas atitudes tomadas são baseadas em conhecimentos populares, sem nenhuma fundamentação teórica, como abanar a vítima, passar álcool no punho, entre outras. Embora soe como uma atitude heróica, algumas ações podem ser perigosas, visto que a consequência de um atendimento de primeiros socorros inadequado pode levar a sequelas permanentes e até ao óbito (PERGOLA; ARAÚJO, 2008; NARDINO et al., 2012).

Os meios de comunicação apontam um crescimento na ocorrência de acidentes e violência na infância, gerando discussões acerca das responsabilidades dos pais e dos responsáveis das instituições de ensino e lazer. A ocorrência repetida destes acidentes na infância reflete em dados epidemiológicos da Secretaria de Vigilância em Saúde do Ministério da Saúde, que apontam as causas externas como a $3^{\mathrm{a}}$ principal causa de morte em crianças de zero a nove anos e a $1^{\mathrm{a}}$ causa de morte entre crianças de 10 a 15 anos (BRASIL, 2011).

Além da alta mortalidade, esses acidentes podem acarretar traumatismos não fatais, levando a desfiguração, encefalopatia anóxica com possíveis déficits neurológicos, exercendo um grande impacto a longo tempo, repercutindo na família, penalizando a criança e levando a danos emocionais, financeiros e sociais (MARTINS, 2006).

Pesquisas que abordam o assunto têm relacionado à ocorrência dos acidentes na infância com características como gênero (maior incidência no sexo masculino), idade da criança, desenvolvimento neuro-psicomotor, características da personalidade e a presença de outras particularidades como deficiência física e/ou mental. Outros fatores predisponentes apontados são: fatores socioeconômicos (renda familiar baixa, escolaridade materna baixa); fatores ambientais (riscos químicos, biológicos, físicos, locais perigosos) e fatores de vulnerabilidade (estresses cotidianos, doença ou perda de um dos pais, pobreza, desigualdades sociais, racismo, escolas deficientes, isolamento social, falta de afeto, violência urbana) (MARTINS, 2006; DEL CIAMPO, 2011; SILVEIRA; PEREIRA, 2011; MARTINS, 2013).

Acidentes no ambiente escolar têm sido descritos na literatura e ocorrem com maior frequência em creches e pré escolas, entre a faixa etária de 0 a 6 anos, fase em que a criança encontra-se em constante descoberta dos objetos que estão ao seu redor, necessitando, por isso, estar sob constante vigilância (BEM et al, 2008; DIAS et al., 2013).

Um acidente que ocorra na escola envolvendo o aluno, além de trazer transtornos para a instituição pode gerar problemas relacionados à responsabilidade legal. A respeito disso, o código penal brasileiro deixa claro com relação à omissão de socorro que deixar de prestar assistência ou não pedir o socorro da autoridade pública constitui crime. Não obstante como o deixar de prestar assistência ou não pedir ajuda configura omissão de socorro, o desconhecimento a respeito das situações de risco eo despreparo dos responsáveis colaboram com o aumento dos riscos podendo levar a sérias complicações ao acidentado, inclusive ao óbito (BRASIL, 1940; MAIA; CAMPOS, 2012; MARANHÃO, 2011; FONTANA; SANTOS, 2014).

Diante de uma situação de acidente na escola, o professor passa pelo estresse de ser ele o responsável pela criança naquele momento, tendo que prestar o primeiro atendimento e encaminhá-la quando necessário, ao serviço médico. O estresse é ainda maior quando o professor não possui noções básicas sobre primeiros socorros, podendo acarretar sérias complicações, o que justifica a necessidade de se investigar o conhecimento destes professores.

Apesar da relevância, o assunto primeiros socorros ainda é pouco difundido, sendo restrito na maioria das vezes aos profissionais de saúde. O profissional enfermeiro, dentro de suas competências, tem o ensino como um instrumento 
capaz de gerar mudanças no perfil de saúde da população por meio da promoção da saúde e prevenção de doenças e agravos, acredita-se que este profissional possa contribuir no ensino de primeiros socorros em ambientes escolares.

Pretende-se com essa pesquisa investigar o conhecimento dos professores de educação básica sobre primeiros socorros a fim de conhecer suas dificuldades e assim elaborar estratégias de ensino sobre o tema.

\section{MÉTODOS}

Trata-se de um estudo de campo exploratório descritivo de abordagem quali-quantitativa. O campo do estudo compreende duas escolas da educação básica: uma de caráter público e outra privada, ambas no município de Lorena, São Paulo. Os sujeitos da pesquisa foram professores da educação infantil e fundamental I (até o nono ano) pertencentes ao quadro fixo das instituições de ensino participantes.

Como instrumento de coleta de dados, foi elaborado um questionário, pré-validado, contendo perguntas de múltipla escolha combinadas com perguntas abertas sobre o tema primeiros socorros. A primeira parte do questionário possui perguntas com o objetivo de caracterizar o perfil dos participantes da pesquisa com relação a sua formação acadêmica, área de atuação e cursos de extensão. A segunda parte do questionário possui nove perguntas de múltipla escolha a respeito de atitudes a serem tomadas em situações de urgência/ emergência afim de identificar o conhecimento dos professores sobre o assunto. Para avaliação e comparação do discurso do professor participante, foi elaborada uma questão de resposta aberta sobre o tema.

Na apreciação qualitativa das questões abertas, foi utilizada a análise de conteúdo por meio da tematização, o que permitiu obter informações na essência subjetiva de cada um, conhecer perspectivas pessoais, buscando uma aproximação com os sujeitos do estudo (FONTOURA, 2011). Os relatos escritos foram analisados seguindo uma sistematização. A princípio as informações coletadas foram exaustivamente lidas, em seguida demarcadas em sua relevância, agrupadas em temas semelhantes, analisadas e interpretadas a luz dos referenciais teóricos. A fim de manter o sigilo dos participantes os mesmos foram categorizados por números.

Para a análise quantitativa, foram utilizados números inteiros e porcentagens.

A pesquisa foi realizada após a apresentação e aceitação da proposta pelas escolas escolhidas e após os professores estarem de acordo com o documento de participação, o Termo de Consentimento Livre e Esclarecido (TCLE). O projeto foi submetido e autorizado pelo Comitê de Ética e Pesquisa da UNIFOA de número 31469014.4.0000.5237.

\section{RESULTADOS}

Participaram da pesquisa 31docentes, os quais 30 eram professoras e 01 professor. Todos os entrevistados informaram possuir ensino superior completo nas áreas de Pedagogia (25), Educação Física (04), Letras (Português/ Inglês) (02) e todos lecionam na educação básica, entre os quais 11 são atuantes apenas na educação infantil, 15 no ensino fundamental I e 5 atuam em ambos níveis de educação, sendo citados também ensino fundamental II, ensino médio e educação especial. O tempo de formação acadêmica dos professores varia de 09 meses a 24 anos, sendo a média de 6 anos e seis meses.

Dos 31 participantes da pesquisa, apenas 10 professores afirmaram ter participado de uma disciplina correspondente a primeiros socorros durante a graduação, sendo que 04 destes na área de Educação Física. 
Ao questionar sobre cursos extra curriculares que abordassem o assunto, 07 professores confirmaram a participação nestes eventos, sendo citados cursos de Brigadista de Incêndio, Curso Técnico em Radiologia, Lesões no Esporte e Primeiros Socorros para Formação de Condutores em autoescola.

Apesar da pouca procura por cursos complementares sobre o assunto, todos os participantes da pesquisa consideraram importante a realização de cursos sobre primeiros socorros sendo relatado no discurso dos professores:

Tema: importância em realizar cursos sobre primeiros socorros.

“Caso haja algum problema em sala de aula, precisamos estar preparados para tal situação” (n²)

“Para saber qual atitude tomar em situações que a criança necessite dos Primeiros Socorros” (n³).

“Com certeza, pois a gente nunca sabe quando iremos precisar socorrer alguém” (nº 6$)$.

Vinte e dois professores afirmaram já ter presenciado uma situação que exigisse conhecimentos básicos sobre primeiros socorros no ambiente escolar. Nota-se que os casos mais relatados foram de sangramento nasal, ferimentos, fraturas e mordeduras (Figura 1).

Situações de crise convulsiva (18\%), desmaio (13\%), picada de animal peçonhento (13\%), hemorragia (9\%), choque elétrico (9\%), crise asmática (9\%), afogamentos (4\%), queimaduras (4\%), intoxicações (4\%) e Parada Cardiorrespiratória- PCR (4\%) também foram citadas pelos professores.

Figura 1 - Situações Vivenciadas pelos professores (N: 31).

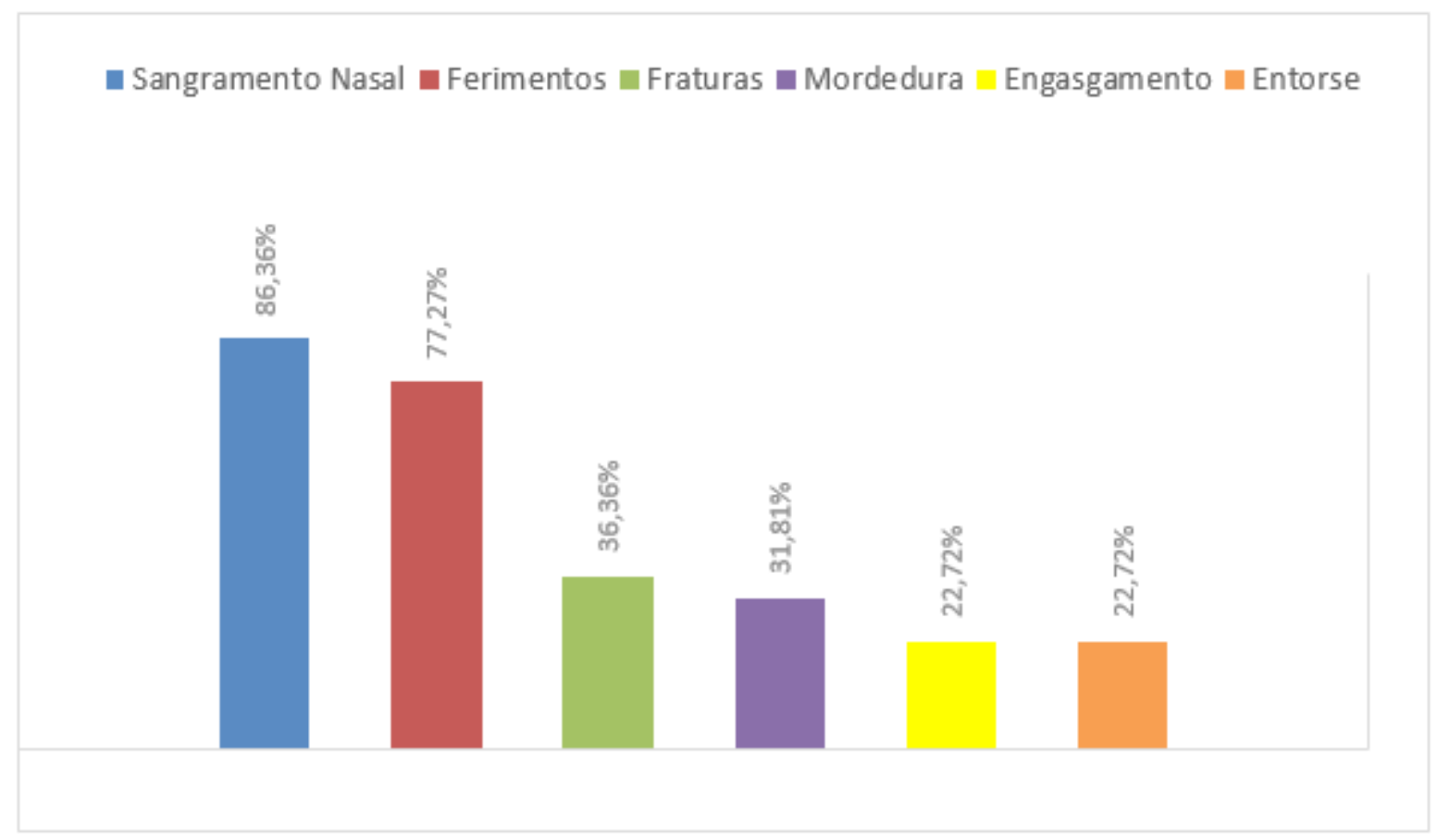

Fonte: autoras.

A fim de avaliar o conhecimento dos professores sobre o assunto, foram elaboradas nove perguntas fechadas de múltipla escolha e uma pergunta aberta. O quadro 1 caracteriza as perguntas de múltipla escolha e o percentual de acerto, erro ou não respondida/ não sabe responder. 
Quadro 1 - Percentual de acertos e erros. (N: 31)

\begin{tabular}{|c|c|c|c|c|c|c|}
\hline \multirow[t]{2}{*}{ Tipo de agravo } & \multicolumn{2}{|c|}{ Respostas corretas } & \multicolumn{2}{|c|}{ Respostas incorretas } & \multicolumn{2}{|c|}{$\begin{array}{c}\text { Não responderam/ } \\
\text { não sabem }\end{array}$} \\
\hline & $\mathrm{N}$ & $\%$ & $\mathrm{~N}$ & $\%$ & $\mathrm{~N}$ & $\%$ \\
\hline Queimadura & 27 & 87 & 4 & 12 & 0 & 0 \\
\hline Crise convulsiva & 24 & 77 & 5 & 16 & 2 & 6 \\
\hline Ferimento & 19 & 61 & 12 & 38 & 0 & 0 \\
\hline Ingestão de produto químico & 19 & 61 & 10 & 32 & 2 & 6 \\
\hline Quebradura dentária & 18 & 58 & 10 & 32 & 3 & 9 \\
\hline Engasgamento & 16 & 51 & 13 & 41 & 2 & 6 \\
\hline Picada de animal peçonhento & 10 & 32 & 19 & 61 & 2 & 6 \\
\hline Quebradura ou torsão & 9 & 29 & 18 & 58 & 4 & 12 \\
\hline Sangramento nasal & 1 & 3 & 26 & 83 & 4 & 12 \\
\hline
\end{tabular}

Fonte: autoras.

Com relação às respostas incorretas assinaladas pelos professores, ao analisarmos as alternativas escolhidas foi possível observar que muitas atitudes são baseadas em conhecimentos populares inadequados ou ultrapassadas, tais como: aplicar gelo em queimaduras, água oxigenada em ferimentos e levantar os braços em situação de engasgamento. O quadro 2 mostra as principais respostas incorretas assinaladas pelos professores.

Quadro 2 - Principais respostas incorretas assinaladas pelos professores.

\begin{tabular}{cc}
\hline Tipo de agravo & Atitude inadequada assinalada \\
\hline $\begin{array}{c}\text { Queimadura } \\
\text { Quebrimentos } \\
\text { Engasgamento }\end{array}$ & $\begin{array}{c}\text { Aplicação de gelo } \\
\text { Aplicação de água oxigenada e algodão } \\
\text { Enrolar membro em pano macio } \\
\text { Virar a criança de cabeça para baixo ou } \\
\text { levantar os braços da criança }\end{array}$ \\
Envenenamento nasal & $\begin{array}{c}\text { Estimular assoar o nariz e inclinar a cabeça para trás } \\
\text { Quebradura dentária }\end{array}$ \\
Picada de animal peçonhento & $\begin{array}{c}\text { Estimulação de vômito e ingestão de água } \\
\text { Enrolar o dente em compressa seca ou } \\
\text { em recipiente com creme dental }\end{array}$ \\
\end{tabular}

Fonte: autoras.

A décima pergunta constitui uma questão aberta, onde o professor é colocado diante de uma situação problema e após a leitura do enunciado, é questionado sobre qual atitude deve ser tomada diante de uma criança em parada cardiorrespiratória (PCR).

Ao realizarmos a análise de conteúdo das respostas qualitativas que se referem à atitude tomada diante de uma criança em PCR, podemos observar um grande despreparo por parte dos professores. As respostas seguintes foram separadas e agrupadas, por evidenciarem que os professores têm algum conhecimento sobre manobras de 
Ressuscitação cardiopulmonar - RCP, contudo as informações contidas nas respostas encontram-se desorganizadas, incompletas ou parcialmente erradas.

Tema: conhecimentos incompletos sobre o atendimento de PCR

"Verifico se a criança está consciente; respiração; verifico pulsação no pescoço; verifico se há ferimentos graves; chamo assistência médica" ( $\left.{ }^{\circ} 12\right)$.

"Imediatamente aplicar os primeiros socorros com respiração boca a boca, para fazer a reanimação da criança” ( $\left.\mathrm{n}^{\circ} 13\right)$.

"Primeiro verifico dentro da boca, chamo resgate, segundo início manobras de respiração cardiorrespiratória. Busco auxílio para que essas atitudes sejam realizadas em menos tempo possível” ( $\left.\mathrm{n}^{\circ} 14\right)$.

Além dos que se arriscaram em responder atitudes de manobras de RCP mesmo que desorganizadas e incompletas, outros evidenciaram por meio de sua resposta, que a criança em PCR ficaria aguardando a chegada do Serviço de Atendimento Móvel de Urgências - SAMU ou Corpo de Bombeiros caracterizando na análise mais um grupo temático:

Tema: apenas chamaria ajuda e aguardaria

“Chamar o SAMU ou Bombeiros”(n³).

“Ligar para o SAMU e depois para os pais" (n 15).

"Imediatamente entraria em contato com o Pronto Socorro, pediria uma ambulância, permaneceria no local até que chegassem, depois tentaria entrar em contato com algum parentesco e não iria embora até que chegasse algum responsável pela criança” $\left(\mathrm{n}^{\circ} 1\right)$.

As respostas seguintes constituem o tema que diz respeito à responsabilidade legal pela criança em situação de risco. É demonstrada em algumas frases a atitude tomada em não mexer em hipótese nenhuma na vítima até que o socorro médico chegue:

Tema: responsabilidade legal, não mexer na vítima.

"O correto é chamar o responsável que está no momento do ocorrido" ( $\left.\mathrm{n}^{\circ} 4\right)$.

"Manteria a calma não mexeria nela e chamava a emergência. Pois não saberia o que fazer" (n 16).

"A primeiro momento não tocaria na criança, nem mudaria ela de lugar. Procuraria alguém da direção da escola para garantir um maior apoio no socorro ao aluno e caso, não encontre ninguém rapidamente, ligaria para a polícia (190) ou para o SAMU (192) para que sejam tomadas as devidas providencias” ( $\left.\mathrm{n}^{\circ} 2\right)$.

"Chamaria socorro e o levaria o mais rápido possível para o hospital através do carro do hospital, pois segundo a lei não devemos colocar alunos em nosso veículo, salvo caso extremo, se a ambulância não chegasse deveria prestar socorro o mais rápido possível”. (n¹7). 


\section{DISCUSSÃO}

A literatura evidencia que o professor de educação física é considerado o mais preparado para lidar com situações de acidentes na escola, pois possui a disciplina de primeiros socorros em sua grade curricular. Quanto aos professores com formação em Pedagogia e Letras, não existe a obrigatoriedade desta disciplina na ementa do curso, sendo o assunto abordado ou não em temas transversais de saúde durante a formação acadêmica (GATTI et al, 2009; ALVES; SILVA, 2011).

Acredita-se que a falta de oferta de cursos extra-curriculares voltados para o público em questão na região estudada, possa ser um dos motivos da falta de formação destes docentes, fato este que motivou o desenvolvimento desta pesquisa. Estudos semelhantes também evidenciaram que os professores vêem a necessidade de treinamento sobre prevenção de acidentes e primeiros socorros por reconhecerem que as fases de crescimento e desenvolvimento da criança as impulsionam a querer descobrir o "novo", favorecendo mais a ocorrência dos acidentes (SENA; RICAS; VIANA, 2008; SILVANE et al, 2008; VIERA et al, 2009).

O fato de 22 professores relatarem já ter vivenciado situações de acidentes em ambiente escolar evidencia a presença destes acidentes e reafirma a necessidade de conhecimentos elementares dos professores responsáveis. As situações vivenciadas pelos participantes da pesquisa são semelhantes a literatura que aponta traumas, cortes, mordidas, escoriações e engasgamento como eventos mais frequentes relatados por professoras da educação infantil (SILVIANE et al., 2008).

Estes resultados vão ao encontro aos fornecidos em um estudo transversal que tomou como base dados do Sistema de Vigilância de Violências e Acidentes - VIVA, do Ministério da Saúde. O estudo apontou que dos 6.897acidentes que envolviam crianças entre 0 a 9 anos, a maioria possuía causas mais comuns associadas em primeiro lugar a quedas, seguidas de queimaduras, ferimentos perfuro-cortantes, acidentes com animais, corpo estranho e outros (MALTA et al., 2012).

O professor diante de uma situação de acidente se vê na incumbência de auxiliar a criança, muitas vezes fazendo uso de conhecimentos populares, que podem ser prejudiciais. Um estudo realizado com 17 colaboradores de uma escola privada de educação infantil de um município de Rio Grande do Sul, também apontou o despreparo e o uso de conhecimentos populares no atendimento de crianças vítimas de acidentes, sendo citado o uso de clara de ovo em queimadura e uso de pomadas sem prescrição médica em ferimentos (FONTANA; SANTOS, 2014).

O sangramento nasal foi o evento mais presenciado pelos professores deste estudo sendo também a questão que obteve maior número de respostas erradas (83\%). Este tipo de hemorragia é muito frequente em crianças e ocorre devido ao rompimento de pequenos vasos sanguíneos nas vias aéreas superiores, podendo estar associado não só a traumas, mas também pela introdução de corpos estranhos, aumento da temperatura, ressecamento do canal nasal, ou por aumento da pressão arterial. Foi também o agravo mais identificado em pesquisas semelhantes. O atendimento desta complicação é bem simples, entretanto, outros autores apontaram as dificuldades de professores em lidar com esta situação (FIORUC et al., 2008).

As respostas abertas dos professores na décima questão evidenciam que existe um conhecimento limitado sobre o atendimento de uma criança desacordada, e que a maioria não mexeria na vítima, apenas chamaria 0 serviço médico de resgate.

Um estudo realizado com 385 sujeitos buscou identificar o nível de informação dos leigos sobre abordagem de vítima em emergência e concluiu que destes, apenas 31\% ao identificar uma pessoa desacordada chamam imediatamente o socorro especializado; quase $17 \%$ não sabem reconhecer presença de sinais de vida e $31 \%$ sequer conhecem o número telefônico do serviço de emergência. O estudo aponta que os leigos possuem conhecimentos incompletos ou incorretos sobre atendimento às vítimas desacordadas (PERGOLA; ARAÚJO, 2008). 
A American Hearth Association - AHA preconiza diretrizes para o atendimento correto em casos de PCR em ambientes extra hospitalares. Essas diretrizes podem e devem ser utilizadas não apenas por profissionais de saúde, mas também por leigos treinados, o que contribui com a melhora das taxas de sobrevivência das vítimas. Essas ações são conhecidas como suporte básico de vida (AHA, 2010).

Sabe-se que em situações de PCR, o tempo gasto entre o evento e o primeiro atendimento é crucial na sobrevida da vítima, e que quanto maior o tempo de espera, menos chances a vítima terá em sobreviver, ou ainda, sobreviver sem sequelas, pois a hipóxia pode levar a danos irreversíveis as células. A massagem cardíaca imediatamente após a constatação da PCR e a desfibrilação precoce são apontados como ações capazes de salvar vidas (AHA; 2010; LYRA et al., 2012; PAZIN FILHO, 2007; PERGOLA; ARAÚJO, 2008).

Diversas experiências positivas de treinamento da população leiga têm sido descritas na literatura, abordando primeiros socorros, situações de PCR, asfixia, manobras de SBV e utilização do desfibrilador externo automático, com participação ativa de crianças em idade escolar, universitários, profissionais de empresas e comércio, professores, entre outros. Fica evidente que a capacitação do leigo para agir em situações de emergência, prestando o primeiro atendimento é imprescindível, pois atitudes assertivas contribuem com as chances de sobrevivência da vítima. (PERGOLA; ARAÚJO, 2008; LYRA et al., 2012; FERREIRA; SOUZA, 2014).

Acredita-se que a divulgação de informações corretas sobre primeiros socorros para os professores participantes da pesquisa poderiam contribuir em um atendimento mais assertivo, no mínimo racional, as crianças vítimas de acidentes, evitando o uso de práticas inadequadas. Essas informações podem ser adquiridas por meio de treinamentos periódicos, oficinas e palestras envolvendo os profissionais da saúde.

\section{CONCLUSÃO}

Acidentes na infância são comuns e também acontecem em ambiente escolar, havendo a necessidade de conhecimentos prévios sobre primeiros socorros pelos professores da educação básica.

A falta de conhecimento técnico científico adequado pode levar a atitudes inadequadas no atendimento de crianças vítimas de acidentes, implicando inclusive no desenvolvimento de sequelas e até a morte.

As ações educativas em saúde devem estar incorporadas no processo de cuidar da enfermagem e ir além do ambiente assistencialista, chegando também no ambiente escolar. Acredita-se que a enfermagem tem muito a contribuir no ensino da saúde em ambiente escolar, fato este, evidenciado por meio desta pesquisa que demonstrou a necessidade do desenvolvimento de cursos, palestras, oficinas sobre o assunto primeiros socorros. 


\section{REFERÊNCIAS}

ALVES, R.F.; SILVA, C.A.F.Trajetória do conteúdo Primeiros Socorros como componente curricular dos cursos de Educação Física das IES do Estado do Rio de Janeiro. Corpus et Scientia. v. 7, n.2, nov. 2011. Disponível em: <http:// apl.unisuam.edu.br/revistas/index.php/corpusetscientia/article/view/135> Acesso em 16 de jun. 2014.

AMERICAN HEART ASSOCIATION. Guidelines CPR ECC 2010. Destaques das Diretrizes American Heart Association para RCP e ACE. Texas. EUA. 2010.

BEM; M.A.M; et al. Epidemiologia dos pequenos traumas em crianças atendidas no Hospital Infantil Joana de Gusmão. Arquivos Catarinenses de Medicina. v. 37, n.2, 2008. Disponível em: <http://www.acm.org.br/acm/ revista/pdf/artigos/550.pdf.>. Acesso em 23 de jun. 2014.

BRASIL. Código Penal Brasileiro. Decreto-Lei n. ${ }^{\circ}$ 2.848, de 7 de Dezembro de 1940. São Paulo: Saraiva, 2001. $35^{\text {aed. }}$

BRASIL. Ministério da Saúde (MS). Secretaria de Vigilância em Saúde. Departamento de Análise de Situação em Saúde. Saúde Brasil 2010: Uma análise da situação de saúde e de evidências selecionadas de impacto de ações de vigilância em saúde. Brasília: MS; 2011.

DEL CIAMPO, L.A.; et al. Características clínicas e epidemiológicas de crianças acidentadas atendidas em um serviço de pronto atendimento. Pediatria. São Paulo, v. 33, n.1, p. 29-34. 2011.

DIAS, M.P.; et al. Identificação dos fatores de risco para acidentes na primeira infância no contexto creche. Atenção Primária a Saúde, Juiz de Fora, MG, v. 16, n.1, p. 20-26, jan/mar. 2013.

FERREIRA, J.; SOUZA, T. V.. Desobstrução de vias aéreas superiores em crianças menores de um ano. Revista Enfermagem Profissional, Rio de Janeiro, v. 1, n. 1, p. 267-275, jan/fev. 2014.

FIORUC, B.E.; et al. Educação em saúde: abordando primeiros socorros em escolas públicas no interior do estado de São Paulo. Eletrônica de Enfermagem. Goiânia, GO,v. 10, n.3, p. 695-702, 2008. Disponível em: <http://www.fen. ufg.br/fen_revista/v10/n3/pdf/v10n3a15.pdf>. Acesso dia 30 de junho de 2014.

FONTANA, R. T.; SANTOS, S.A.P. Educação em Saúde sobre primeiros socorros a partir dos saberes dos professores. Vivência. v. 10, n. 18, p. 133-146, maio, 2014. Disponível em: http://www.reitoria.uri.br/ vivencias/Numero_018/ artigos/pdf/Artigo_11.pdf. Acesso em 07 de julho de 2014.

FONTOURA, H.A. Tematização como proposta de análise de dados na pesquisa qualitativa. In: FONTOURA, H.A. Formação de professores e diversidades culturais: múltiplos olhares em pesquisa. Niterói: Intertexto, 2011, p. 61-83.

GATTI, B.A.; et al. Formação de professores para o ensino fundamental: estudo de currículos das Licenciaturas em Pedagogia, Língua Portuguesa, Matemática e Ciências Biológicas. São Paulo: Fundação Carlos Chagas. Departamento de Pesquisas Educacionais. V. 29, março 2009.

LYRA, P.F.; et al..Programa de educação em reanimação cardiorrespiratória: ensinando a salvar vidas. Revista Brasileira de Educação Médica. Rio de Janeiro, v. 36, n.4, 570-573, 2012.

LOPES, E.M.; ANJOS, S.J.S.B.; PINHEIRO, A.K.B.. Tendência das ações de educação em saúde realizadas por enfermeiros no Brasil. Revista de enfermagem da UFRJ, Rio de Janeiro, v.17, n.2, p. 273-277, abr/jun. 2009.

MAIA, G.; CAMPOS, R.. Segurança para crescer. Saúde e Meio Ambiente. Mafra, SC, v.1, n.1, junho, 2012. Disponível em: <http:// www.periodicos.unc.br/index.php/sma/article/download/224/267>. Acesso em 26 de junho de 2014.

MALTA, D.C.; et al. Acidentes e violência na infância: evidências do inquérito sobre atendimentos de emergência por causas externas - Brasil, 2009. Ciência e Saúde Coletiva, Rio de Janeiro, v. 17, n.9, p. 2247-2258. 2012. 
MARANHÃO, D.G..O conhecimento para preservar a vida: um tema delicado. Veras Cruz - Vera Cruz, v.1, n.2, 2011. Disponível em: <http://iseveracruz.edu.br/revistas/index.php/revistaveras/article/viewArticle/56>. Acesso em 27 de junho de 2014.

MARTINS, C.B.G.. Acidentes e violências na infância e adolescência: fatores de risco e de proteção. Revista Brasileira de Enfermagem, Brasília, v. 66, n. 4, p. 578-584, jul/ago. 2013.

MARTINS, C.B.G. Acidentes na infância e adolescência: uma revisão bibliográfica. Revista Brasileira de Enfermagem, Brasília, v.59, n.3, p.344-348, maio- jun. 2006.

NARDINO, J.; et al.. Atividades educativas em primeiros socorros. Contexto e Saúde. Ijuí, v. 12, n. 23, p. 88-92, jul/ dez. 2012.

PAZIN FILHO, A.; et al.. Simulação de pacientes - cursos de suporte de vida da ACLS, BLS e PALS na FMRP- USP. Medicina, Ribeirão Preto, v. 40, n.2, p. 2014-212, abr/jun. 2007.

PERGOLA, A.M.; ARAÚJO, I.E.M.. O leigo em situação de emergência. Escola de Enfermagem da USP, São Paulo, v. 42, n. 4, p. 769-776, 2008. Disponível em :<http://www.scielo.br/pdf/reeusp/v42n4/v42n4a20.pdf >. Acesso em 07 de julho de 2014.

SENA, S.P.; RICAS, J.; VIANA, M.R.A.. A percepção dos acidentes escolares por educadores do ensino fundamental, Belo Horizonte. Revista Médica de Minas Gerais, Belo Horizonte, MG, v. 18, n.4, s.1, p. 47-54. 2008. Disponível em:<http://rmmg.medicina.ufmg.br/index.php/rmmg/article/viewFile/127/109.> Acesso em 30 de junho de 2014.

SILVANE, C.B; et al..Prevenção de acidentes em uma instituição de educação infantil: o conhecimento das cuidadoras. Revista de enfermagem UERJ, Rio de Janeiro, v.16, n.2, p.200-205, abr./jun. 2008.

SILVEIRA, D. C.; PEREIRA, J.T.. Acidentes prevalentes em crianças de 1 a 3 anos em um pronto-socorro de Belo Horizonte no ano de 2007. Revista Mineira de Enfermagem, Belo Horizonte, MG, v. 15, n. 2, p.181-189, abr/jun. 2011.

VARELLA, D.; JARDIN, C..Primeiros socorros: um guia prático. São Paulo: Claro enigma, 2011. 7 p.

VERONEZE, A.M.; et al.. Oficinas de Primeiros socorros: relato de experiência. Gaucha de Enfermagem. Porto alegre, v. 31, n. 1, p. 179-182, 2010.

VIEIRA, L.J.E.S.; et al. Ações e possibilidades de prevenção de acidentes com crianças em creches de Fortaleza, Ceará. Ciência e Saúde Coletiva, Rio de Janeiro, v. 14, n. 5, 1687-1697. 2009. 